\title{
Responses of Two Contrasting Genotypes of Rice to Brown Planthopper
}

\author{
Yuanyuan Wang, Xiaolan Wang, Hongyu Yuan, Rongzhi Chen, Lili Zhu, Ruifeng He, and Guangcun He \\ Key Laboratory of Ministry of Education for Plant Development Biology, College of Life Sciences, Wuhan University, \\ Wuhan 420072, P.R. China
}

Submitted 12 February 2007. Accepted 5 September 2007.

Rice (Oryza sativa L.) and brown planthoppers (BPH) (Nilaparvata lugens Stål) provide an ideal system for studying molecular mechanisms involved in the interactions between plants and phloem-feeding insects. The phenotypic responses and changes in transcript profiles of seedlings representing two rice cultivars differing in resistance to the BPH were analyzed. In the BPH-compatible (susceptible) cv. MH63, BPH feeding reduced three examined plant growth parameters (leaf area expansion, height increases, and dry weight increases) and photosynthetic rates of the leaves. In the BPH-incompatible (resistant) cv. B5, BPH feeding caused slight reductions in protein and sucrose contents, but the plants maintained their photosynthetic activity and grew normally. A cDNA microarray containing 1,920 suppression subtractive hybridization clones was used to explore the transcript profiles differences in the two cultivars under control and BPH-feeding conditions. In total, 160 unique genes were detected as being significantly affected by BPH feeding in rice plants, covering a wide range of functional categories, and there were 38 genes that showed the similar transcript pattern in both genotypes. The physiological responses and transcript profiles of plants represented in both genotypes suggested that multiple pathways might be involved in reprogramming of BPHinfested rice plants. The differences in transcript levels between the compatible and incompatible interactions revealed in this study were not only the reaction of resistance and susceptibility but also reflections of different damage rates and genotypic backgrounds of the rice cultivars.

Additional keywords: BPH-responsive gene, plant-herbivore interactions.

The productivity of rice (Oryza sativa L.), the staple food for nearly $35 \%$ of the global population, is unfavorably affected by a number of stresses, both biotic (including pathogenic viruses, bacteria, fungi, and herbivorous insects) and abiotic (e.g., wounding, flooding, adverse soil conditions, and extreme temperatures). One of the problematic insects is the brown planthopper (BPH) (Nilaparvata lugens Stål), a specialist herbivore of rice found throughout Asia that frequently causes heavy losses of rice crop yields. These insects draw nutrients from the phloem of rice plants using their stylet mouthparts. High BPH

Corresponding author: G. He; E-mail: gche@whu.edu.cn; Telephone: +86 27 68752384; Fax: +862787214327.

* The $e$-Xtra logo stands for "electronic extra" and indicates a supplemental figure and two supplemental tables are available online. populations (thousands per susceptible plant in some cases) can destroy a plant in a short period of time (Huang et al. 2001; Yang et al. 2002). Large numbers of planthoppers cause the infested plants to become brown and dry. This condition, called hopperburn, kills the plants. Even if the planthopper population density is not high enough to kill the plants, BPH feeding may reduce yields (Watanabe et al. 1997).

BPH can consume more than $28 \%$ of the total dry matter of rice plants infested at the reproductive stage (Sogawa 1994). $\mathrm{BPH}$ also transmit ragged stunt and grassy stunt diseases (Matthews 1991). There have been many reports on the effects of BPH feeding on physiological properties of rice plants, including photosynthetic rate (Watanabe and Kitagawa 2000), leaf nitrogen concentration (Sogawa 1982), nutrient uptake (Wu et al. 2003), hormone content, and plant growth parameters (Wu et al. 2004). These studies show that planthopper infestations reduce photosynthesis or alter the translocation of photosynthates. Metabolic changes in rice plants following $\mathrm{BPH}$ infestation also have been reported (Cagampang et al. 1974). In order to understand the effects of BPH feeding on rice plants that cause, inter alia, the severe reduction in yields and death of susceptible plants, the molecular mechanisms involved need to be elucidated.

Plant responses to herbivore attack can be correlated to the mode of feeding and the amount of tissue damage occurring at the feeding site (Walling 2000). Unlike chewing insects, phloem-feeding insects have evolved to survive on a nutritionally imbalanced diet of phloem sap and to minimize wound responses in the host plants (Thompson and Goggin 2006). To date, most studies on phloem-feeding insects investigate aphid interactions (De Vos et al. 2005; Ellis et al. 2002; Fidantsef et al. 1999; Kaloshian et al. 2000; Li et al. 2004; Martinez de Ilarduya et al. 2003; Moran and Thompson 2001; Voelckel et al. 2004; Zhu-Salzman et al. 2004). By examining the RNA levels of plant defense-related genes after aphid feeding, many studies show that RNAs from salicylic acid (SA)-regulated genes are most prominent, whereas jasmonic acid (JA)- and ethylene (ET)-regulated defense responses are induced transiently, are smaller in magnitude, or are suppressed (De Vos et al. 2005; Kaloshian and Walling 2005; Moran et al. 2002; Martinez de Ilarduya et al. 2003; Moran and Thompson 2001). SA- and JA-induced defenses clearly can coexist, and unique temporal and spatial programs have been displayed in each plant-insect interaction (Kaloshian and Walling 2005). For example, silverleaf whitefly (Bemisia tabaci type B) feeding induces SA defenses and suppresses effectual JA defenses in Arabidopsis thaliana (Zarate et al. 2007). Unlike the silverleaf whitefly-Arabidopsis interaction (Zarate et al. 2007), JA- and ET-regulated genes respond to silverleaf whitefly feeding in tomato and squash (van de Ven et al. 2000; Walling 2000). 
Compared with aphid or whitefly studies, little information was available on the molecular mechanisms involved in rice responses to $\mathrm{BPH}$ until several recent investigations provided new insights. Notably, using a macroarray of 108 cDNAs, Zhang and associates (2004) investigated changes in expression levels of genes associated with plant responses to feeding by chewing insects, pathogen infection, wounding, and other stresses in plant responses to $\mathrm{BPH}$ feeding. They found that expression levels of various genes that are upregulated in plants in response to chewing insects were mostly unchanged or downregulated, suggesting that defense mechanisms against BPH differ from those against chewing insects. However, in an investigation of a susceptible rice cultivar by Yuan and associates (2005), genes involved in macromolecule degradation and plant defenses were found to be upregulated, whereas those involved in photosynthesis and cell growth were downregulated following $\mathrm{BPH}$ infestation. In addition, wild rice $(O$. minuta) subjected to BPH infestation elevated expression of defense-related genes, and enhanced metabolic activities were observed (Cho et al. 2005).

Host plant resistance is an important component of integrated pest management systems against $\mathrm{BPH}$ in rice production. In the last 10 years, a number of BPH-resistant rice genotypes have been selected and genes for BPH resistance have been mapped on chromosomes (Hirabayashi and Ogawa 1995; Huang et al. 2001; Yang et al. 2002). Understanding the molecular responses of the resistant genotypes should provide a solid foundation for developing effective strategies to improve the $\mathrm{BPH}$ resistance of rice. However, relatively few studies have compared physiological responses or changes in transcript levels between resistant and susceptible rice genotypes under $\mathrm{BPH}$ infestation. Here, the comparisons of the responses to $\mathrm{BPH}$ feeding of two contrasting rice genotypes were presented, mainly based on transcript profiling and physiological measurements. B5, an introgression line carrying BPH resistance genes from wild rice (O. officinalis) shows high resistance to $\mathrm{BPH}$, whereas MH63 is a popular cultivar that is susceptible to BPH. In this study, B5 and MH63 are not related genotypes; however, comparisons are useful because isogenic lines are not currently available. These rice genotypes are well characterized and resources such as subtracted cDNA libraries are available; therefore, they are useful systems for studying $\mathrm{BPH}$ resistance mechanisms (Huang et al. 2001, Ren et al. 2004, Yuan et al. 2005). Results presented here should enhance their utility in this respect and facilitate attempts to elucidate the mechanisms involved in rice responses to BPH and other phloem-feeding insects.

\section{RESULTS}

\section{Physiological changes \\ in contrasting genotypes of rice under BPH attack.}

Genotype MH63 is a fertility-restoring line for a number of hybrid rice cultivars and is highly susceptible to BPH. B5 is an introgression line selected from progenies of wide hybridization programs involving wild rice, O. officinalis (Yang et al. 1999), which has been shown to contain two major resistance genes and two quantitative trait loci (QTL) against BPH (Huang et al. 2001; Ren et al. 2004). When subjected to BPH feeding for 2 days, nearly half of the insects caged with B5 seedlings died, while most of the insects on the plants of MH63 survived. The damage score caused by BPH infestation in susceptible genotype MH63 was higher than that in the resistant genotype B5 in each replicate (Table 1). There were pronounced differences in the symptoms and physiological properties displayed by these two genotypes (Table 2). For the resistant genotype B5, the height, green leaf area, and dry weight of the infested plants were not markedly reduced compared with the noninfested B5 plants. The plants showed few symptoms of damage and grew normally. In contrast, all the tested growth parameters decreased significantly in BPHinfested plants of the susceptible genotype MH63 (Table 2A).

Table 1. Survival rate of brown planthopper $(\mathrm{BPH})$ insects and damage score of rice seedlings ${ }^{\mathrm{x}}$

\begin{tabular}{|c|c|c|c|c|c|c|c|c|}
\hline \multirow[b]{2}{*}{ Cultivars } & \multirow[b]{2}{*}{ BPH survival $(\%)^{\mathrm{z}}$} & \multicolumn{6}{|c|}{ Damage score of rice plant ${ }^{y}$} & \multirow[b]{2}{*}{ Response to $\mathrm{BPH}$} \\
\hline & & 1 & 2 & 3 & 4 & 5 & 6 & \\
\hline B5 & $52.99 \pm 1.48$ & 0.20 & 0.30 & 0.17 & 0.23 & 0.33 & 0.13 & Resistant \\
\hline MH63 & $88.41 \pm 3.37$ & 2.17 & 1.77 & 2.30 & 1.90 & 1.83 & 1.90 & Susceptible \\
\hline
\end{tabular}

${ }^{\mathrm{x}}$ Data was recorded after 2 days of feeding of second to fourth instar BPH nymphs on rice plants at a density of 10 insects per seedling. Each replicate comprised 30 seedlings.

${ }^{\mathrm{y}}$ Damage score of rice plant were measured according to the scale described by Huang and associates (2001). Results are mean values of 30 seedlings of each replicates.

${ }^{\mathrm{z}}$ Survival ratio of BPH insect. Results are mean values of six replicates \pm standard error.

Table 2. Physiological parameters of resistant B5 and susceptible MH63 plants after 2 days of feeding by brown planthoppers ${ }^{\mathrm{Z}}$

\begin{tabular}{|c|c|c|c|c|c|c|}
\hline Parameters & B5 control & B5 infested & $\begin{array}{c}\text { Decrease } \\
(\%)\end{array}$ & MH63 control & MH63 infested & $\begin{array}{c}\text { Decrease } \\
(\%)\end{array}$ \\
\hline \multicolumn{7}{|l|}{ Growth parameters } \\
\hline Height $(\mathrm{cm})$ & $33.11 \pm 1.87 \mathrm{~A}$ & $32.71 \pm 1.93 \mathrm{~A}$ & 1.21 & $32.15 \pm 2.05 \mathrm{~A}$ & $30.57 \pm 1.63 \mathrm{~B}$ & 4.92 \\
\hline Leaf area $\left(\mathrm{cm}^{2}\right)$ & $14.02 \pm 1.30 \mathrm{~A}$ & $13.75 \pm 1.19 \mathrm{~A}$ & 1.93 & $13.59 \pm 0.66 \mathrm{~A}$ & $12.80 \pm 1.09 \mathrm{~B}$ & 5.81 \\
\hline Dry weight (g/10 seedlings) & $2.0773 \pm 0.0127 \mathrm{~A}$ & $2.0679 \pm 0.0124 \mathrm{~A}$ & 0.45 & $1.7567 \pm 0.0228 \mathrm{~A}$ & $1.0246 \pm 0.0407 \mathrm{~B}$ & 41.68 \\
\hline \multicolumn{7}{|l|}{ Macromolecule content } \\
\hline Protein content (mg/g of FW) & $40.46 \pm 1.48 \mathrm{~A}$ & $38.90 \pm 1.29 \mathrm{~A}$ & 3.86 & $39.16 \pm 0.60 \mathrm{~A}$ & $33.65 \pm 2.29 \mathrm{~B}$ & 14.07 \\
\hline Leaf sucrose content (mg/g of FW) & $13.51 \pm 0.32 \mathrm{~A}$ & $12.79 \pm 0.46 \mathrm{~B}$ & 5.33 & $11.55 \pm 0.63 \mathrm{~A}$ & $9.26 \pm 0.98 \mathrm{~B}$ & 19.83 \\
\hline Stem sucrose content (mg/g of FW) & $6.15 \pm 0.17 \mathrm{~A}$ & $5.55 \pm 0.31 \mathrm{~B}$ & 9.76 & $4.72 \pm 0.19 \mathrm{~A}$ & $2.43 \pm 0.84 \mathrm{~B}$ & 48.51 \\
\hline \multicolumn{7}{|l|}{ Photosynthetic parameters } \\
\hline Chlorophyll content (mg/g of FW) & $1.98 \pm 0.15 \mathrm{~A}$ & $1.97 \pm 0.14 \mathrm{~A}$ & 0.51 & $1.96 \pm 0.17 \mathrm{~A}$ & $1.74 \pm 0.24 \mathrm{~B}$ & 11.23 \\
\hline Photosynthetic rate $\left(\mu \mathrm{mol} \mathrm{m}{ }^{-2} \mathrm{~s}^{-1}\right)$ & $18.64 \pm 2.44 \mathrm{~A}$ & $18.63 \pm 2.33 \mathrm{~A}$ & 0.05 & $18.22 \pm 1.98 \mathrm{~A}$ & $8.87 \pm 2.90 \mathrm{~B}$ & 51.32 \\
\hline Stomatal conductance $\left(\mathrm{mol}\right.$ water $\mathrm{m}^{-2} \mathrm{~s}^{-1}$ ) & $7.04 \pm 0.53 \mathrm{~A}$ & $7.04 \pm 0.55 \mathrm{~A}$ & 0 & $5.78 \pm 0.56 \mathrm{~A}$ & $3.15 \pm 1.14 \mathrm{~B}$ & 45.5 \\
\hline Transpiration rate $\left(\mathrm{mmol}\right.$ water $\left.\mathrm{m}^{-2} \mathrm{~s}^{-1}\right)$ & $0.77 \pm 0.08 \mathrm{~A}$ & $0.75 \pm 0.09 \mathrm{~A}$ & 2.6 & $0.60 \pm 0.08 \mathrm{~A}$ & $0.46 \pm 0.20 \mathrm{~B}$ & 23.33 \\
\hline
\end{tabular}

${ }^{\mathrm{z}}$ Results are mean values of six replicates \pm standard error. Each replicate comprised 10 seedlings. For each cultivar, mean values in a row followed by the same upper case letter are not significantly different between the control and infested plants at the $P$ value $<0.01$ using Students $t$ test. FW $=$ fresh weight. 
Visual damage appeared in MH63 seedlings within 2 days of BPH infestation. The plants turned yellow, brown, and dry from the lowest leaf upward, and finally died when BPH feeding continued for 2 weeks. The protein, leaf sucrose, and stem sucrose contents all decreased in both the resistant genotype B5 and the susceptible genotype MH63 when BPH fed on them (Table 2B). However, the reductions in MH63 were much greater than those in B5. During BPH feeding, the chlorophyll level, net photosynthetic rate, stomatal conductance, and transpiration rates showed no change in the resistant B5 but decreased significantly in the susceptible MH63 (Table 2C). Thus, the growth and photosynthesis parameters of the BPHsusceptible MH63 plants were severely reduced, whereas those of the BPH-resistant B5 remained relatively constant following $\mathrm{BPH}$ infestation.

\section{Changes in transcript profiles}

of the contrasting rice genotypes to $\mathrm{BPH}$ attack.

Healthy B5 and MH63 plants have similar growth and physiological parameters (Table 2). However, MH63 is a highly susceptible line and B5 is a highly resistant line to BPH (Table 1). To explore changes in transcript profiles in the resistant and susceptible plants under BPH-feeding conditions, cDNA microarray analyses were performed. In all, 960 clones were selected randomly from the suppression subtractive hybridization (SSH) cDNA library of BPH-infested rice seedlings of B5 and MH63, respectively (Wang et al. 2005; Yuan et al. 2005). DNAs of 1,920 clones were amplified and arrayed on slides in double spots $(3,840$ elements per slide). To test the quality of the cDNA microarray, homotypic hybridizations and hybridizations between two independent pooled samples were performed first, and then scatter plots were generated to examine the consistency of the results (Fig. 1). Only a few probes with low signal intensities $(<100)$ fell outside of the range of 2.0fold relative intensity differences between the two fluorescent dyes (Fig. 1A), and most of the probes clustered tightly near the diagonal of the plot. In contrast, we observed a higher variability between the two independent pooled samples and the scatter plot was slightly more dispersed (Fig. 1B). Results indicate that the microarrays were credible.

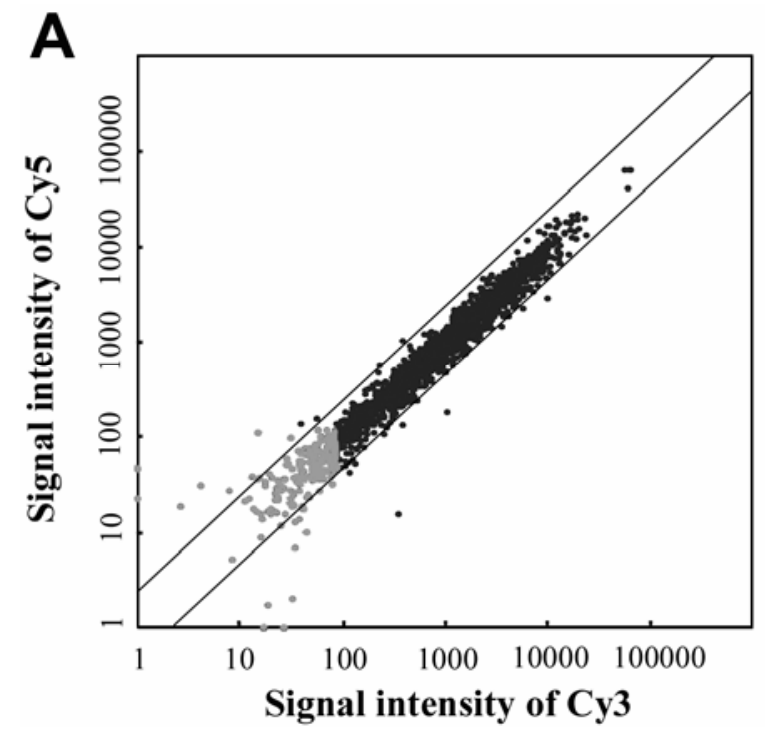

After hybridization with the targets prepared from rice seedlings infested by BPH insects and the controls, the slides were scanned and the signal data were analyzed (see Material and Methods for details). The microarray data processing included loess normalization within slide and quantile normalization between slides to remove the systematic errors. To identify $\mathrm{BPH}-$ responsive genes, the Limma R package was used to perform pairwise comparison, and a moderated $t$ statistic was computed for each gene of treated sample versus control sample (Smyth 2004). Rigorous criteria of false discovery rate (FDR)adjusted $P$ value less than 0.05 and twofold or more change in signal intensity of the treated sample against that of the control sample were used. The same criteria were applied for both B5 and MH63. The signal intensities of noninfested B5 and MH63 were compared with display genetic divergence between the two lines. Most of the 1,920 clones (96.5\%) showed similar transcript levels between the two noninfested rice lines (Supplemental Figure 1A). Between the infested B5 and MH63, $90.9 \%$ of clones showed the similar transcript levels.

Based on the hybridization signals obtained, 194 clones ( $10.1 \%$ of the 1,920 clones) were identified as differentially regulated. The nucleotide sequences of the 194 clones were analyzed and their putative functions were identified by comparing them to the National Center for Biotechnology Information database using the BLAST program. According to similarity searches, the 194 clones represent 160 unique genes (Table 3). BLAST results revealed that 130 of these unique genes encoded proteins with proposed functions, 11 were ho-

Table 3. Summary of brown planthopper-responsive expressed sequence tags based on cDNA microarray hybridization

\begin{tabular}{lcc}
\hline Genes & Number & Ratio $(\%)^{\mathbf{z}}$ \\
\hline Total clones & 194 & $\ldots$ \\
Unique genes & 160 & 100 \\
BLAST-matched & 130 & 81.25 \\
Known function & 119 & 74.38 \\
Unknown function & 11 & 6.88 \\
BLAST-no matches & 30 & 18.75 \\
\hline
\end{tabular}

${ }^{\mathrm{z}}$ Percentage of the unique genes.

B

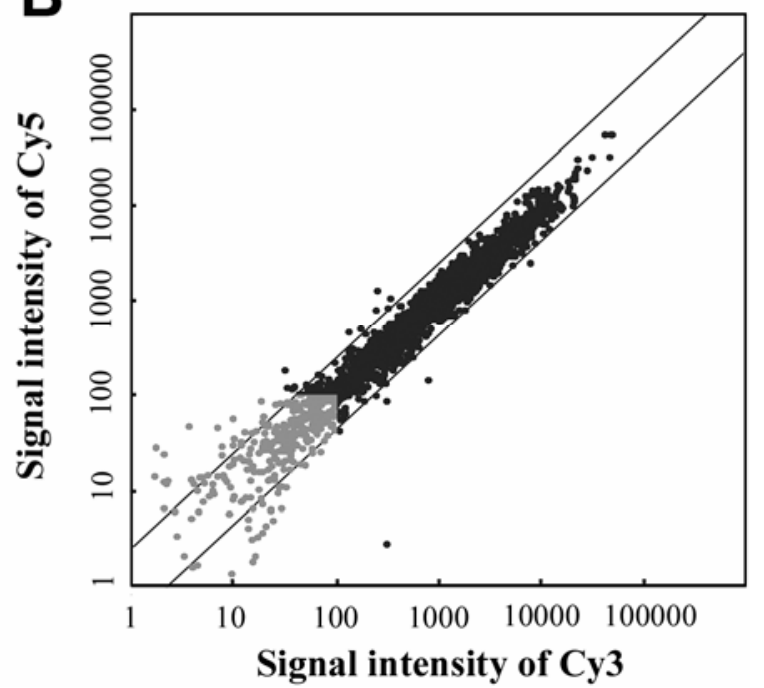

Fig. 1. Reproducibility of hybridizations and independent experiments. B5 control sample was randomly selected to hybridize. A, Reproducibility of hybridizations. RNAs from the same sample were labeled with Cy3 and Cy5, respectively, and hybridized to the same microarray. A scatter plot comparing the $\log 10$ raw fluorescent signal intensities of Cy3 and Cy5 is shown, indicating that $98.33 \%$ of the expressed sequence tags (ESTs) were within a twofold range and most of the variable ESTs had low signal intensities $(<100)$. B, Reproducibility of independent experiments. RNAs from different pooled samples harvested under the same conditions at different times were labeled with $\mathrm{Cy} 3$ and Cy5, respectively, and hybridized to the same microarray. A scatter plot comparing the log 10 raw fluorescent signal intensities is shown. 
mologous to unknown proteins or cDNA clones from rice or other plants, and the remaining 29 did not meet the match criteria $\left(E\right.$ value $\left.<\mathrm{e}^{-8}\right)$. The GenBank dbEST accession numbers, lengths, BLASTn results, putative functions, functional categories, and microarray data of the 160 unique clones are listed in Supplemental Table 2. Among the 160 genes, 95 genes came from SSH library of B5 and 65 genes from MH63.

After feeding by BPH for $48 \mathrm{~h}$, mRNA levels changed for 128 genes in the resistant B5 plants and 74 genes in the susceptible MH63 plants. Upon BPH feeding, 45 genes in total showed a decrease in their mRNA levels, but more genes (83) demonstrated enhanced mRNA levels in B5. In MH63, the numbers of genes showing increased mRNA levels and decreased mRNA levels was equal (Fig. 2). The percentage of genes showing higher mRNA levels by BPH stress in MH63 was $50 \%$, lower than the percentage in B5 (64.84\%).

A Venn diagram was used to visualize the change patterns of the differentially expressed genes in BPH-infested rice (Fig. 2 ). The 160 identified genes were classified into seven groups. The mRNA levels of 42 genes were differentially changed in both the resistant B5 and susceptible MH63 cultivars, and 38 genes showed similar expression patterns in both resistant and susceptible cultivars.

\section{Categories of genes differentially expressed in the contrasting genotypes.}

Among the BPH-responsive genes selected, 130 unique genes matched plant genes encoding proteins with proposed functions. To classify the putative functions of these BPH-responsive genes, the proteins putatively encoded by the BPH-responsive genes were aligned with Arabidopsis proteins using the Munich Information Center for Protein Sequences (MIPS) functional categorization system (Frishman et al. 2001). A high proportion of the genes $(35.39 \%)$ identified in this way were grouped into functional category 99 (unclassified function), and the genes with no functional category were determined to be $13.08 \%$. Apart from these genes, the major categories represented were metabolism (13.85\%); cell rescue, defense, and virulence $(12.31 \%)$; subcellular localization $(9.23 \%)$; protein fate $(6.92 \%)$; cellular transport/transport mechanisms $(6.15 \%)$; cellular communication or signal transduction mechanism $(4.62 \%)$;

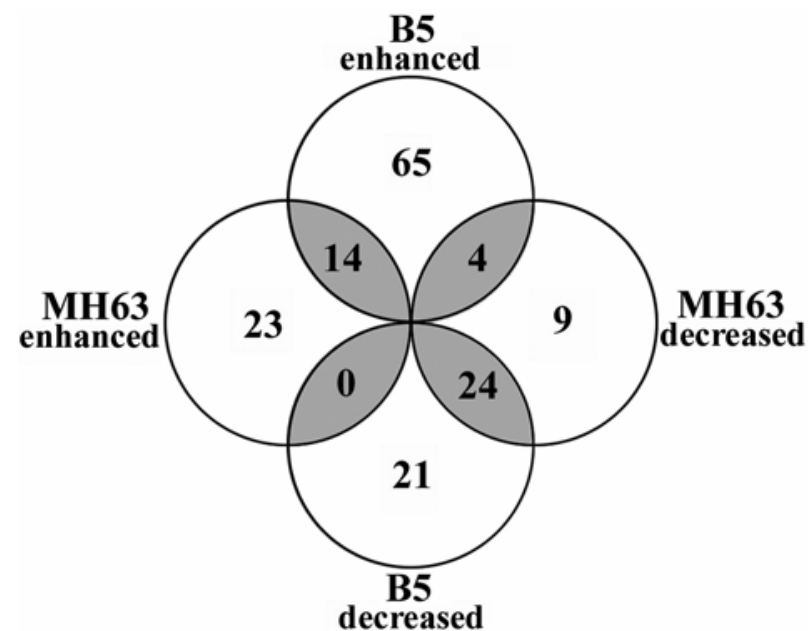

Fig. 2. Venn diagram showing the classification of the brown planthopperresponsive genes identified in the microarray analysis. The identified genes were classified into seven groups: mRNA abundances enhanced in B5 only, decreased in B5 only, enhanced in MH63 only, decreased in MH63 only, enhanced in B5 and enhanced in MH63, enhanced in B5 and decreased in MH63, and decreased in B5 and decreased in MH63. No identified genes showed decreased mRNA abundances in B5 but increased in MH63. and biogenesis of cellular components (4.62\%). The categories of transcription $(3.85 \%)$, protein with binding function or cofactor requirement $(3.85 \%)$, protein synthesis $(2.31 \%)$, and energy $(2.31 \%)$ were of relatively low abundance. The results indicate that BPH feeding induced a reorganization of the transcriptome and multiple response pathways in the rice plants.

Comparison of the categories of the genes encoding proteins with proposed functions in B5 and MH63 shows clear differences between the contrasting genotypes (Fig. 3). In the resistant genotype B5, most or all genes in 11 of 17 categories showed higher mRNA levels (Fig. 3A), and genes in 9 categories increased in transcript levels in the susceptible genotype MH63 (Fig. 3B). The results suggest that rice coped with BPH attack by enhancing the expression of a wide range of genes.

\section{RNA blot analysis}

of selected expressed sequence tags (EST).

A key issue to ascertain was the degree to which the physiological changes observed in the BPH-infested plants related to corresponding changes in the transcriptome. Thus, because reductions were observed in protein and sucrose contents in
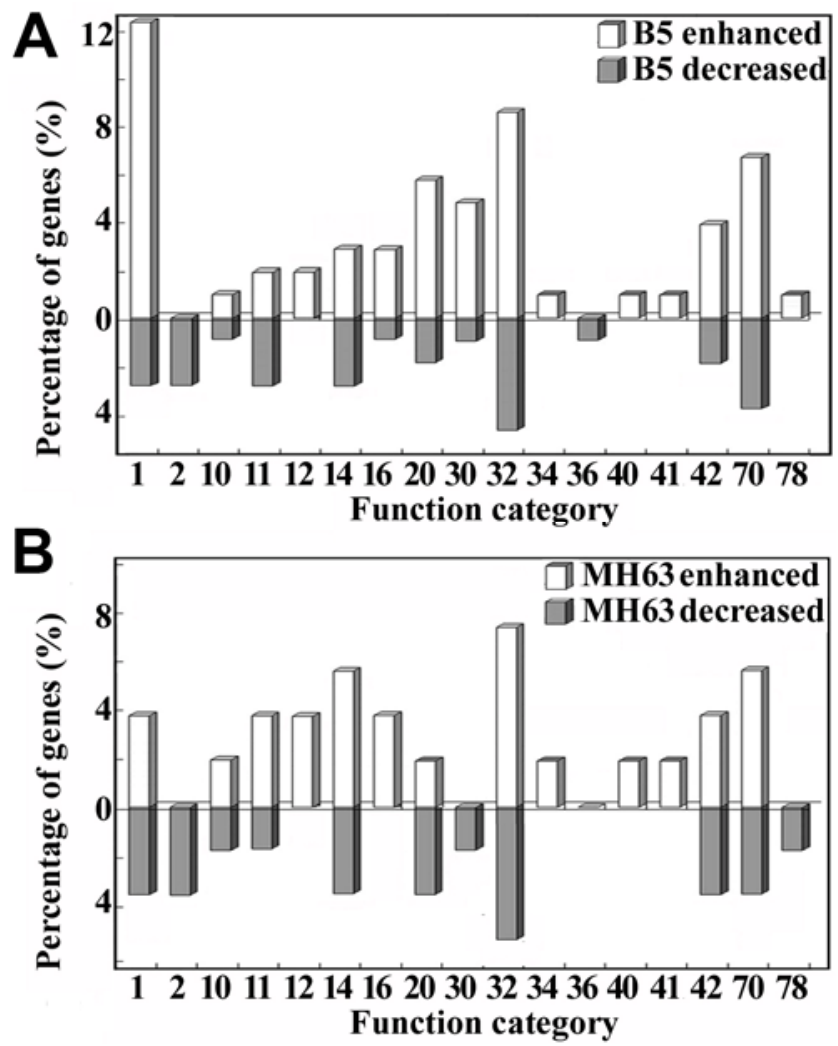

Fig. 3. Functional classifications and comparative analysis of the brown planthopper (BPH)-responsive genes encoding proteins with proposed functions in B5 and MH63. A, In all, 128 clones with proposed functions from BPH-infected B5 were categorized. B, In all, 61 clones with proposed functions from BPH-infected MH63 were categorized. The percentages of each functional category are shown. The functional categories are: 1, metabolism; 2, energy; 10, cell-cycle and DNA processing; 11, transcription; 12, protein synthesis; 14, protein fate (folding, modification and destination); 16, protein with binding function or cofactor requirement (structural or catalytic); 20, cellular transport, transport facilitation and transport routes; 30 , cellular communication or signal transduction mechanism; 32, cell rescue, defense and virulence; 34, interaction with the cellular environment; 36, interaction with the environment; 40, cell fate; 41, development; 42, biogenesis of cellular components; 70, subcellular localization; 78, ubiquitous expression; 98, classification not yet clear; 99, unclassified proteins; and ND, not determined. Data for unclassified and not-determined genes are not shown. 
both B5 and MH63 under BPH infestation, attention was focused on six genes known to be directly involved in protein degradation and processes that reduced sucrose levels. RNA blot was used to confirm the results of microarray for the select set of six genes (Figs. 4 and 5). We found good congruence between methods in both B5 and MH63, using the rice 18 s rRNA gene as control.

Using RNA blot, it was found that the mRNA abundances of a ubiquitin conjugating enzyme gene (BPHiOO1), the ClpX gene (BPHiO13), and an aspartic proteinase encoding gene (BPHiO24) were enhanced in MH63 but not B5, and the mRNA abundances of a serine protease-like protein gene (BPHiw025) and a rice proteinaceous cysteine proteinase inhibitor (cystatin) gene (BPHiw085) were enhanced in B5 but not MH63 after infestation by BPH. Cystatins may inhibit virus-induced protein degradation in plant leaves (Gholizadeh et al. 2005). BPHiw062 representing a gene encodes pyrophosphate fructose-6-phosphate-1-phosphotransferase (PPi-PFP), which plays a crucial role at a key regulatory site in plant carbohydrate metabolism (Heldt 1997). It is thought that PPi-PFP is able to improve ATP generation in glycolysis reactions (Plaxton 1996) and may provide advantages to organisms in specific niches. Message abundance of BPHiw062 was enhanced in B5 but decreased in MH63. The major component of assimilates in phloem taken by $\mathrm{BPH}$ is sucrose. Therefore, the increased expression of PPi-PFP may be a key part of the process whereby the resistant rice adjusts sucrose metabolism in responses to BPH.

Timecourse expression analysis of BPHiw062 and BPHiw085 was conducted to see how these genes respond to BPH infestation in B5 and MH63 (Fig. 5B). Shoots were sampled 3, 6,
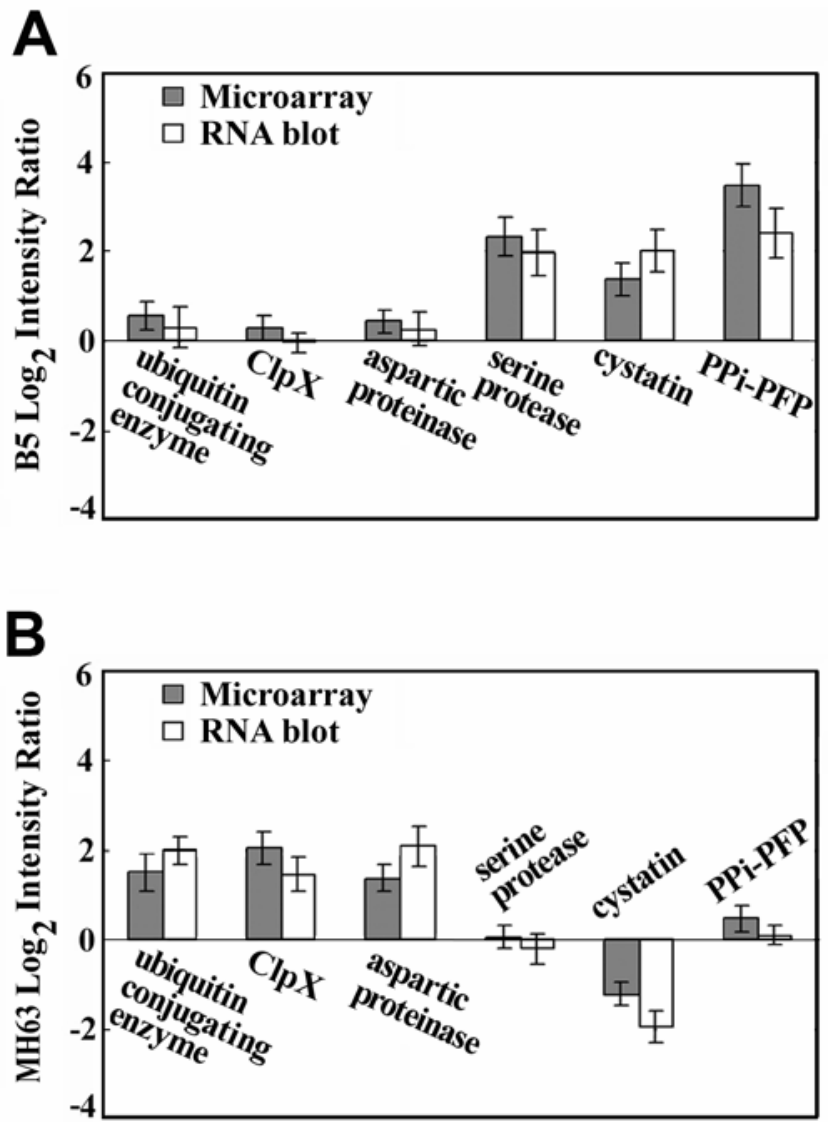

Fig. 4. Mean intensity ratio estimates for selected brown planthopper-responsive genes compared with microarray and RNA blot methods in both A, B5 and B, MH63. PPi-PFP = pyrophosphate fructose-6-phosphate-1phosphotransferase.
$12,24,48,72$, and $96 \mathrm{~h}$ after addition of $\mathrm{BPH}$ and transcripts of the genes were isolated. The level of the PPi-PFP RNAs (BPHiw062) rapidly increased within $3 \mathrm{~h}$ and reached peak levels within $48 \mathrm{~h}$ after the start of BPH feeding in B5, but decreased within $6 \mathrm{~h}$ in MH63. Cystatin RNAs (BPHiw085) began to increase in B5 within $6 \mathrm{~h}$ and increased continually during BPH feeding, but remained unchanged in MH63.

\section{Chromosomal distribution of BPH-responsive genes.}

The chromosomal distributions of the BPH-responsive EST were investigated by using BLASTn against the Gramene rice genome database, and 129 of them were mapped electronically. The numbers of EST on the 12 rice chromosomes is shown in Table 4. The chromosome with the highest number was chromosome 2, followed by chromosomes $3,4,5$, and 9 , for all of which there were more than 10 EST. Chromosome 10 had the fewest EST. The numbers of EST on the remaining chromosomes was 6 to 10 . Following the method developed by Walia and associates (2005), two gene clusters were found on chromosome 2 and one cluster on chromosome 9 (Fig. 6), in which several coregulated genes were in very close proximity in the resistant cv. B5. Qbp4, one of the QTL contributing to $\mathrm{BPH}$ resistance, is flanked by markers G293 and RM205 $(22,437,219$ to $22,720,811 \mathrm{bp})$ (Ren et al. 2004) and fell into the gene cluster on rice chromosome 9 (Fig. 6B). This result suggests that several regions of the B5 genome may contain coordinately regulated genes associated with responses to $\mathrm{BPH}$.

The regions of BPHiw077 (chromosome 3; 35,493,892 to 35,494,053 bp) and BPHiw047 (chromosome 12; 22,594,374 to $22,594,586 \mathrm{bp}$ ) were found to be close to two different major BPH resistance genes, Qbp2 (Huang et al. 2001) and Bph18(t) (Jena et al. 2006), respectively (Fig. 7). BPHiw077 encodes an acyl-CoA synthetase and BPHiw047 encodes a calmodulinbinding protein TCB60. The transcript level of BPHiw047 was rapidly enhanced, within $3 \mathrm{~h}$, by $\mathrm{BPH}$ infestation in $\mathrm{B} 5$ but was decreased within $24 \mathrm{~h}$ in MH63 (Fig. 5B). The expression level of BPHiw077 was increased within $12 \mathrm{~h}$ in B5, but no obvious change in its transcript level was observed in MH63 in response to $\mathrm{BPH}$.

\section{DISCUSSION}

To elucidate transcript responses of plants to biotic or abiotic stress, using isogenic lines serves as one of the best choices (Fukao et al 2006). However, isogenic lines are not always available. Although the lack of isogenic lines limited our ability to make certain comparisons, contrasting genotypes were used as an alternative strategy. Healthy B5 plants are similar to MH63 in plant height, dry weight, and many morphological characters (Table 2). Between the noninfested B5 and MH63 plants, $96.5 \%$ of the 1,920 clones showed similar transcript levels. BPH feeding on the susceptible MH63 resulted in differential expression of 74 genes, which included 38 genes that showed similar expression patterns in the resistant B5 (Fig. 2). The results showed that there were overlaps between the responses in B5 and MH63 to BPH feeding. By using contrasting genotypes, this study provided useful information for understanding of rice-BPH interactions.

Like plant-pathogen interactions, both compatible and incompatible plant-herbivore interactions occur (Kaloshian and Walling 2005; Thompson and Goggin 2006). Just as in the incompatible plant-insect interactions, effector molecules from the specific insect biotype can trigger the resistance conferred by the relevant plant resistance genes (Dangl and Jones 2001; Kaloshian and Walling 2005). In the genotypes used in this experiment, MH63 is a BPH-susceptible cultivar carrying no 
major resistance gene against $\mathrm{BPH}$, whereas two genes, Bph14 and Bph15, are in the BPH-resistant cv. B5 (Huang et al. 2001). cDNA microarray analysis was used to compare the transcript profiles of a compatible interaction and an incompatible interaction, in this case the BPH-MH63 interaction and BPH-B5 interaction, respectively, after $48 \mathrm{~h}$ of $\mathrm{BPH}$ infestation.

To date, the majority of published studies have focused on plant transcript profiles of compatible interactions with phloem-feeding insects for which no genetic variation in resistance levels has been identified. Relatively few studies have examined plant transcript profiles in incompatible plant-herbivore interactions (Thompson and Goggin 2006). Studies that compare insect-responsive gene expression in incompatible and compatible interactions are designed to identify a subset of genes that are directly related to innate resistance (Park et al. 2006; Qubbaj et al. 2005; Zhang et al. 2004). In the study of interaction between apple and the rosy apple aphid after $72 \mathrm{~h}$ of infestation, only six transcript changes were unique to the incompatible interaction by utilizing cDNA amplified fragment length polymorphism and RNA blot analyses (Qubbaj et al. 2005). Aside from three genes which were regulated genotype specifically, BPH-responsive genes identified in resistant rice plants showed similar expression patterns in the susceptible rice cultivar after $72 \mathrm{~h}$ of $\mathrm{BPH}$ infestation (Zhang et al. 2004). A high degree of overlap was revealed between plant transcript profiles directly related to innate resistance in compatible and incompatible interactions with phloem-feeding insects (Qubbaj et al. 2005; Thompson and Goggin 2006; Zhang et al. 2004).

On the other hand, transcriptional differences evidently were observed between resistant and susceptible sorghum lines in response to greenbug feeding (Park et al. 2006). In this

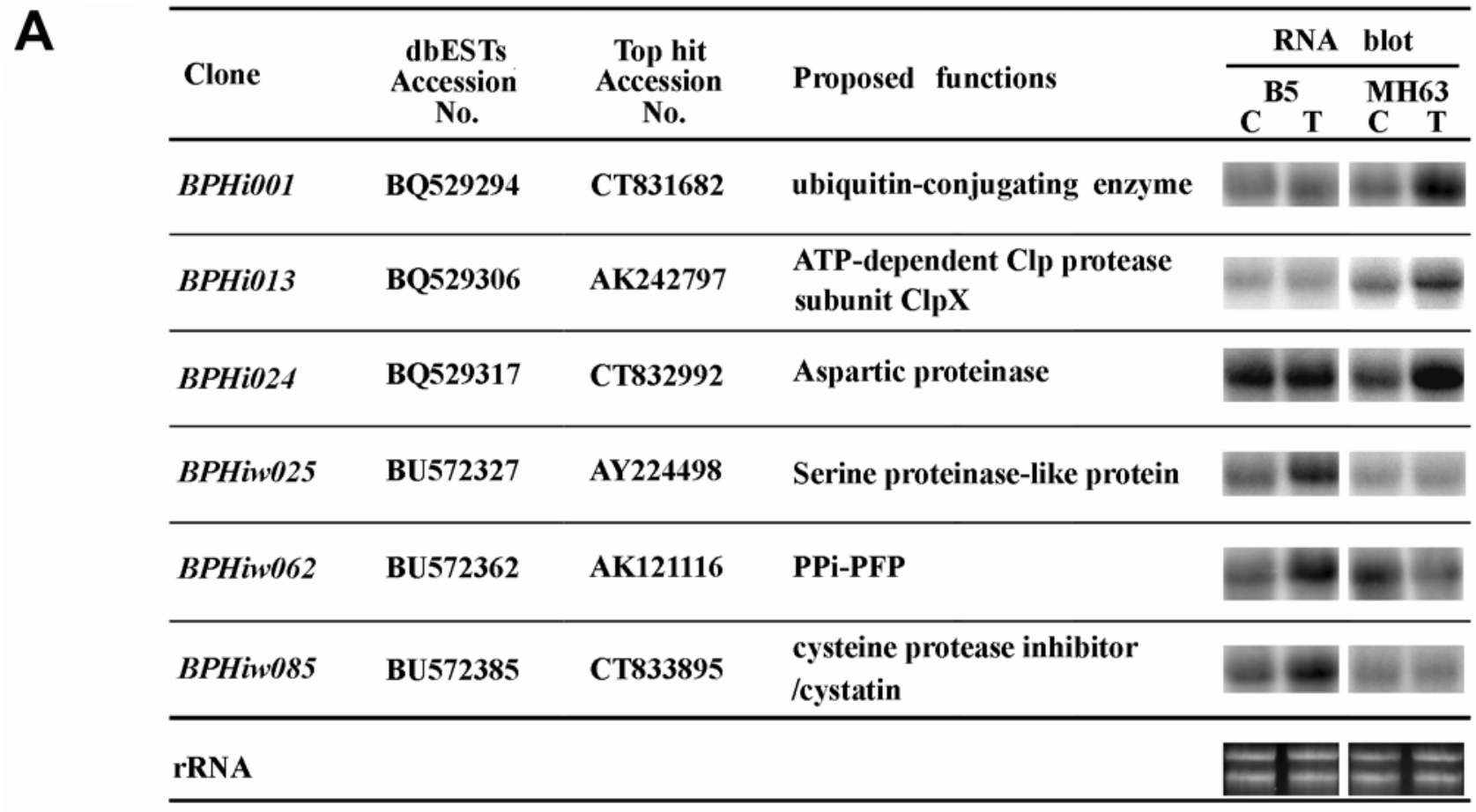

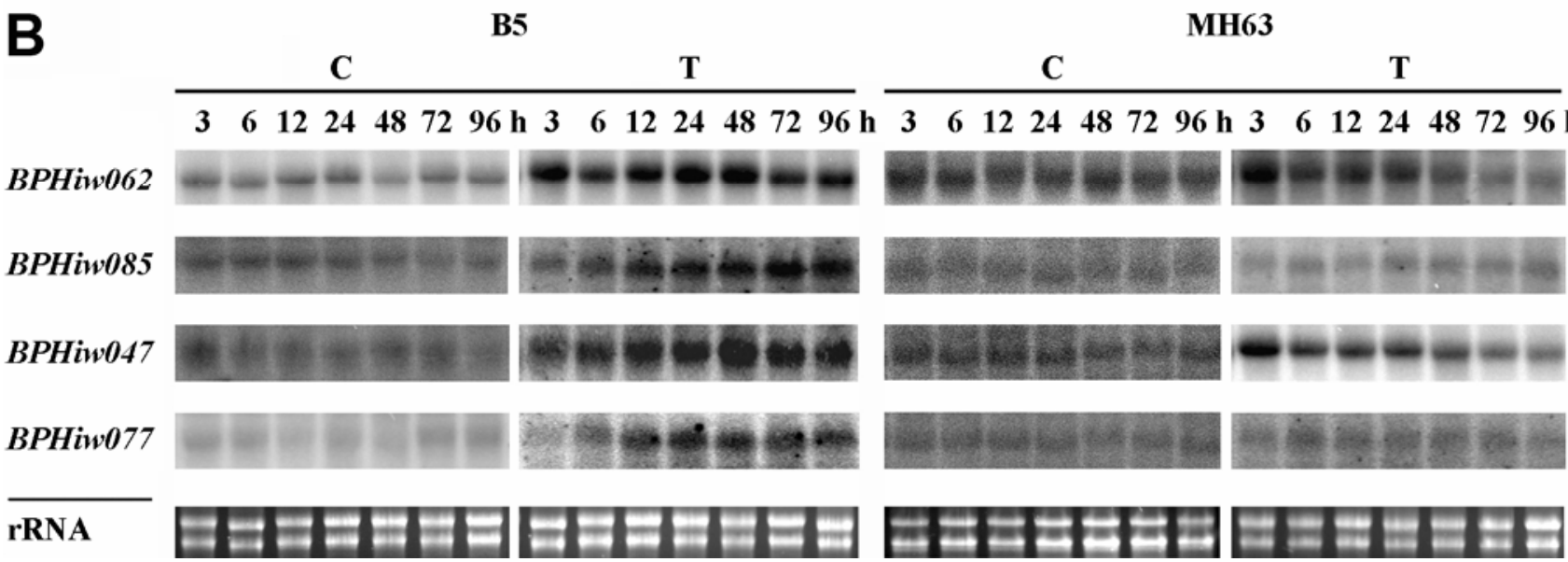

Fig. 5. Expression profiles obtained from the cDNA microarray and RNA blot analyses of selected brown planthopper (BPH)-responsive genes. A, RNA blot verification of selected genes directly involved in protein degradation. Total RNAs from noninfested rice seedlings (C) and from rice seedlings exposed to $\mathrm{BPH}$ for $48 \mathrm{~h}(\mathrm{~T})$ were used for the RNA blot analysis $(30 \mu \mathrm{g} / \mathrm{lane})$. B, Time course of expression of selected BPH-responsive genes. Each RNA blot lane was loaded with $30 \mu \mathrm{g}$ of total RNA isolated from seedlings exposed to BPH treatment for 3, 6, 12, 24, 48, 72, or $96 \mathrm{~h}$ (T). Total RNAs from noninfested rice seedlings harvested at the same time were used as the controls (C). rRNA stained with ethidium bromide was used as a loading control. PPi-PFP $=$ pyrophosphate fructose-6-phosphate-1-phosphotransferase. 
study, most BPH-responsive genes showed different expression patterns between compatible and incompatible interactions after $48 \mathrm{~h}$ of BPH infestation, and eight of them were confirmed by using RNA blots. BPH induce a lot of phenotypic changes in their host plants, many of which are indirectly related to innate resistance and transcriptionally regulated. After $48 \mathrm{~h}$ of BPH feeding, the leaves of the susceptible MH63 began to wilt and the growth and photosynthesis parameters were reduced, whereas the resistant B5 had few scorch symptoms and otherwise appeared healthy (Table 2). The difference in transcript level between the compatible interaction and incompatible interaction represented in this study not only was caused by the rice resistance genes against BPH but also was affected by different phenotypic changes and genotypic backgrounds in the rice cultivars. Furthermore, resistance is due to differences in the timing and magnitude of plant defenses, rather than to qualitatively different responses (Thompson and Goggin 2005). For example, a PPi-PFP gene (BPHiw062) and a TCB60 gene (BPHiw047) were expressed in an accelerated manner in the incompatible interaction, and the two genes also were expressed but decreased gradually in the compatible interaction (Fig. 5B). Therefore, future transcriptional studies should examine earlier time points in the rice-BPH interaction, and consider the temporal and spatial components of plant responses to $\mathrm{BPH}$ by using isogenic lines.

In the resistant cv. B5, the only detected physiological changes following $\mathrm{BPH}$ infestation were the minor reductions in protein and sucrose content; most of the physiological parameters remained at control levels. The results suggested that there was an active and successful resistance mechanism to

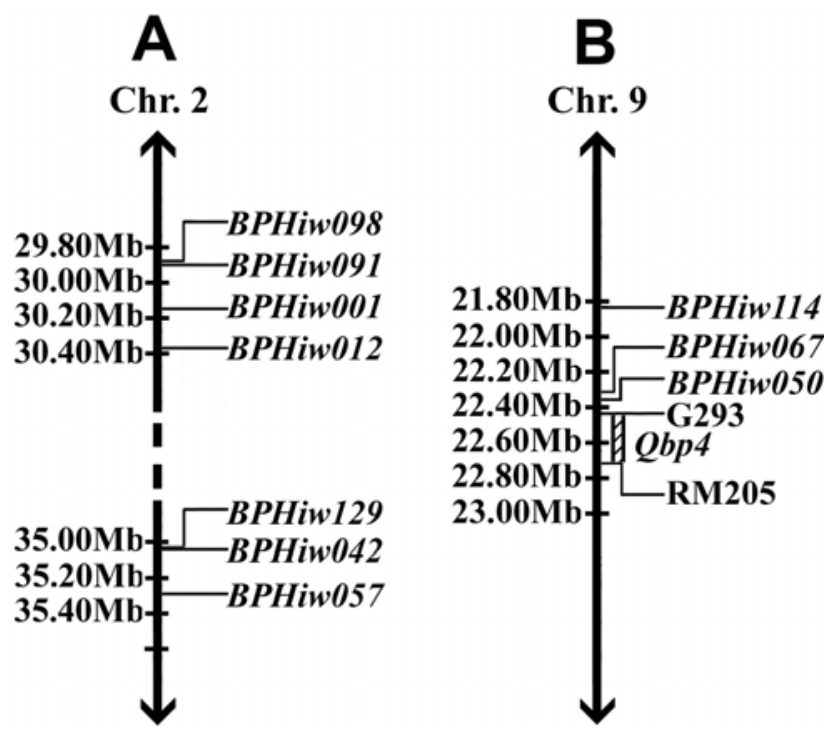

Fig. 6. Rice genes induced in B5 under brown planthopper (BPH) stress that co-localize to the same region. The following gene clusters were identified: A, Four-gene cluster and three-gene cluster on chromosome $2(29,879,809$ to $30,367,956$ and $35,037,485$ to $35,292,303 \mathrm{bp}$; respectively). B, Three-gene cluster on chromosome 9 (21,840,643 to 22,363,715 bp). The Qbp4 locus, which is flanked by the markers G293 and RM205 on this chromosome, falls into this cluster.
BPH infestation in resistant rice B5. Successful resistance mechanisms to different stresses usually operate via the enhancement of metabolic pathways involved in cell rescue, defense, and signal transduction (Scheideler et al. 2002). At least under BPH infestation, a genetic advantage is mediated by transcriptional reorganization fueling biosynthetic pathways directed toward the synthesis of defense elements (Rossignol et al. 2006). Similarly, Cho and associates (2005) found that the resistance of wild rice to insect infestation was achieved by the elevated expression of defense-related genes and enhanced metabolic activities, including glycolysis, the Krebs cycle, and the pentose phosphate pathway. The results of functional classification and comparative analyses in this study show that most of the responsive genes in the cellular communication and signal transduction, metabolism, cellular transport, cell rescue, and defense categories increased mRNA levels in the resistant genotype following BPH attack (Fig. 3). Moreover, transcripts levels of genes involved in the biogenesis of cellular components and subcellular localization also increased after BPH feeding in the resistant genotype. Subcellular localization is a key functional characteristic of proteins, which must be localized in appropriate cellular compartments to perform specific physiological functions. Thus, the findings indirectly imply that new proteins and other macromolecular components may be synthesized in resistant rice cultivars as components of active defenses.

\section{A}
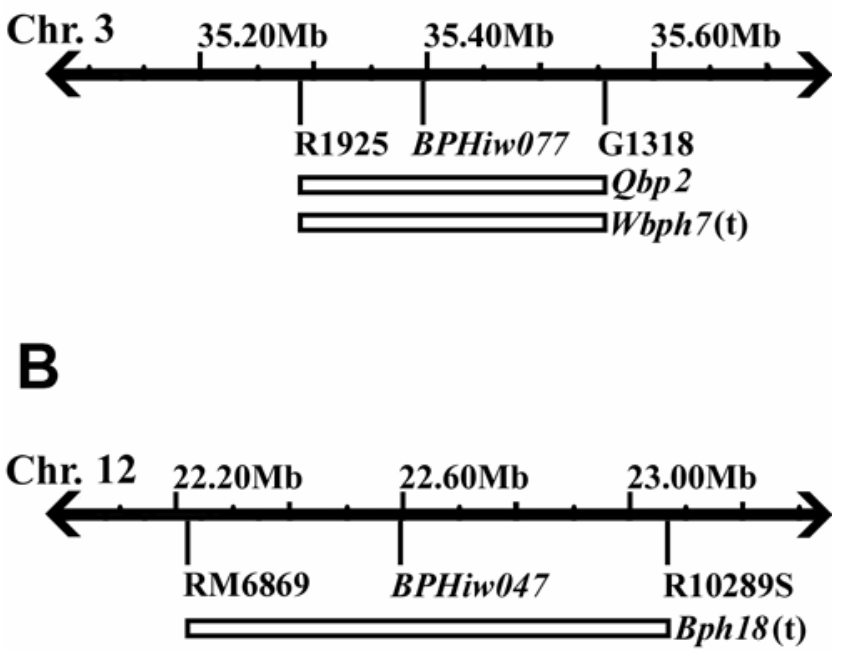

Fig. 7. Chromosomal segment associated with two major quantitative trait loci (QTLs) for brown planthopper (BPH) resistance. A, $Q b p 2$ is flanked by markers R1925 and G1318 on chromosome 3 (35,385,979-35,657,000 bp) (Huang et al. 2001). Tan and associates (2004) identified a major QTL for whitebacked planthopper resistance $\operatorname{Wbph} 7(\mathrm{t})$ in the same region. The region of BPHiw077 (chromosome 3; 35,493,892 to 35,494,053 bp) was close to $Q b p 2$. B, Bph18(t) is flanked by markers RM6869 and R10289S on chromosome 12 (22,219,512 to 23,063,949 bp) (Jena et al., 2006). The region of BPHiw047 (chromosome 12; 22,594,374 to $22,594,586 \mathrm{bp}$ ) was close to $\operatorname{Bph} 18(\mathrm{t})$.

Table 4. Chromosomal distribution of brown planthopper-responsive expressed sequence tags (ESTs)

\begin{tabular}{|c|c|c|c|c|c|c|c|c|c|c|c|c|c|}
\hline \multirow[b]{2}{*}{ Cultivar } & \multicolumn{13}{|c|}{ Number of ESTs on each chromosome (Chr) } \\
\hline & Chr 1 & Chr 2 & Chr 3 & Chr 4 & Chr 5 & Chr 6 & Chr 7 & Chr 8 & Chr 9 & Chr 10 & Chr 11 & Chr 12 & Total \\
\hline B5 & 7 & 20 & 16 & 12 & 11 & 7 & 6 & 5 & 10 & 1 & 4 & 6 & 105 \\
\hline MH63 & 5 & 10 & 8 & 3 & 8 & 4 & 3 & 3 & 1 & 2 & 6 & 2 & 55 \\
\hline Total & 9 & 24 & 18 & 14 & 14 & 10 & 7 & 7 & 11 & 2 & 7 & 6 & 129 \\
\hline
\end{tabular}


Overall, the results show that BPH feeding caused distinctly differing levels of physiological and morphological damage to the resistant and susceptible rice plants. BPH feeding reduced the photosynthetic rate by $51.3 \%$ in the susceptible rice cv. MH63. Almost every plant transcript profiling that has been done has revealed that photosynthesis-related gene RNAs decline in response to some phloem-feeding insect infestation, such as aphid (Qubbaj et al. 2005; Voelckel et al. 2004; ZhuSalzman et al. 2004), BPH (Wang et al. 2005; Yuan et al. 2005), and whitefly (Kempema et al. 2007). Photosynthetic activity is highly correlated with leaf $\mathrm{N}$ concentration (Hasegawa and Horie 1996), especially the soluble protein content (Makino et al. 1983). In the susceptible plants, the severe decrease in nitrogen content and photosynthetic activity may cause the significant dry weight reductions observed. In addition, almost half of the sucrose content in the stem of the susceptible rice plants was lost in 2 days by BPH ingesting it; consequently, nonstructural carbohydrate accumulation presumably was reduced markedly in the stem. Reduction of nonstructural carbohydrates in susceptible rice leaves may be attributed to the reduction of photosynthesis by BPH feeding. Translocation of photosynthates from the leaves to the roots was blocked by BPH feeding (Kabrick and Backus 1990). The decline in production of assimilates and the disruption of the translocation of assimilates in susceptible rice may change the amounts of carbohydrates reaching the roots and this, in turn, may impede the uptake of nutrients from roots because they are essential for the maintenance of root activity (Rubia-Sanchez et al. 2003).

In our study, three instances where mRNA abundance-enhanced genes are tightly clustered in the B5 genome were found. Recently, several examples of neighboring genes in eukaryotic genomes having similar expression patterns were provided (Spellman and Rubin 2002; Walia et al. 2005). The experimental design of microarray experiments may influence the outcome (Thompson and Goggin 2005). According to the microarray data in this study, the clustered genes did not have clustered functions. However, an interesting instance was found on rice chromosome 7 where physically clustered salinity stressrelated genes grouped to the same functional branch (Walia et al. 2005). It is not known whether there is an advantage for the genome to maintain these presumably functionally related gene clusters. One model suggests it to be due to incidental expression of genes close to each other not being discriminated by the regulatory machinery ( $\mathrm{Li}$ et al. 2005). An alternative model suggests the possibility of clusters corresponding to regions of active machinery (Chang et al. 2004).

Genes that localize to a QTL region and have transcript abundance associated with the QTL trait become interesting candidates for further detailed analysis. The region of an acylCoA synthetase gene (BPHiw077) was close to a major QTL for $\mathrm{BPH}$ resistance, which was mapped on rice chromosome 3 (Fig. 7A). This QTL, called $Q b p 2$, is flanked by markers R1925 and G1318 (Huang et al. 2001). Other investigators (Tan et al. 2004) have identified a major QTL for whitebacked planthopper resistance $W b p h 7(\mathrm{t})$ in the same region of chromosome 3. The acyl-CoA synthetase in the chloroplast is considered to play a key role in reactivating all fatty acids leaving the plastids. A second well-characterized function of acyl-CoA synthetase is the activation of fatty acids for $\beta$-oxidation (Fulda et al. 1997). The region of a calmodulin-binding protein TCB60 gene (BPHiw047) was close to another major resistance gene, $B p h 18(\mathrm{t})$, which was identified in an introgression line (IR65482-7-216-1-2) and localized within a 0.843-Mb physical interval between the markers R10289S and RM6869 on chromosome 12 (Fig. 7B) (Jena et al. 2006). Calmodulinbinding proteins play important roles in response to biotic and abiotic stresses and development (Zielinski 1998). In the
$\mathrm{BPH}-\mathrm{B} 5$ interaction, transcript levels of the two genes were enhanced more rapidly than in the BPH-MH63 interaction. Whether the difference in expression patterns is due to allelic variation at this locus between the two rice genotypes will be studied in the future.

\section{MATERIALS AND METHODS}

\section{Plant materials and BPH treatments.}

The BPH colony (Nilaparvata lugens, biotype1) used for infestation was maintained on rice plants of cv. Taichung Native 1 (TN1) grown under fluorescent and incandescent lights $\left(150 \mu \mathrm{E} \mathrm{m}^{-2} \mathrm{~s}^{-1}\right)$ at day and night temperatures of 28 and $25^{\circ} \mathrm{C}$, respectively, with $80 \%$ relative humidity under long-day $(14 \mathrm{~h}$ of light and $10 \mathrm{~h}$ of dark) conditions in the Genetics Institute of Wuhan University. TN1 seed were sown in 25-cm-diameter pots containing standard fertilized soil. Second to fourth instar nymphs of BPH were collected from infested plants and used for infestation experiments.

The seed of BPH-resistant rice $\mathrm{B} 5$ and $\mathrm{BPH}$-susceptible MH63 were germinated and then planted in pots $(8 \mathrm{~cm}$ in diameter and $15 \mathrm{~cm}$ in height) filled with standard fertilized soil. Twenty seedlings were grown per pot under controlled conditions with $150 \mu \mathrm{E} \mathrm{m}^{-2} \mathrm{~s}^{-1}$ fluorescent and incandescent lights, day and night temperatures of 28 and $25^{\circ} \mathrm{C}$, respectively, $80 \%$ relative humidity, and light and dark cycles of 14 and $10 \mathrm{~h}$, respectively, in the greenhouse. Each pot was covered with a nylon screen bag $(15$ by $35 \mathrm{~cm})$. Weak plants were removed when the seedlings were in the three-leaf stage and 15 seedlings were kept in each pot. To infest with BPH, 150 instar nymphs were collected in each 20-ml Falcon tube, and each Falcon tube was placed upright in each pot. BPH were released by unscrewing the cuvette. After infestation for the fixed time, the BPH were removed from the plants by aspiration. Stems and leaves of the seedlings were harvested, frozen in liquid nitrogen, and stored at $-80^{\circ} \mathrm{C}$ for further analysis. Seedlings that had not been fed upon by BPH were harvested at the same fixed time, as controls.

\section{Growth parameter investigations and statistical analysis.}

For growth parameter investigation, the numbers of surviving BPH insects were counted and the damage score of plants was measured by using the criteria described by Huang and associates (2001) after 2 days of infestation (Supplemental Table 1). Six replicates were used for evaluating the survival ratios of $\mathrm{BPH}$ and plant damage scores of rice. Each replicate was conducted with 30 seedlings. Mean and standard error values for each parameter were calculated.

The BPH then were removed from the plants by aspiration and the following growth and physiological parameters were measured: the height of each seedling from the stem base to the longest leaf top was measured, its green leaf area was estimated using the conversion factor published by Zhu and Kang (1996), and its dry weight was estimated by weighing it after incubation at $80^{\circ} \mathrm{C}$ until its weight remained constant. Total protein contents were estimated following the method of Bradford (1976), recording the absorbance of extracts spectrophotometrically at $595 \mathrm{~nm}$ on a Shimadzu UV-1601 spectrophotometer (Tokyo) and using bovine serum albumin as a calibration standard. The chlorophyll of the leaves was extracted in $80 \%$ acetone at $-20^{\circ} \mathrm{C}$ (Arnon 1949) and spectrophotometrically determined (UV-1601, Shimadzu) at 646 and $663 \mathrm{~nm}$, then calculated using the equation published by Arnon (1949). The total soluble sugar contents of leaf tissues and stem tissues were extracted separately using hot $80 \%$ ethanol. To measure sucrose in the soluble sugar extracts, 2 $\mathrm{M} \mathrm{NaOH}$ solution was added to the extraction mixture to de- 
stroy reducing sugars, and then sucrose concentration was determined by the anthrone $/ \mathrm{H}_{2} \mathrm{SO}_{4}$ method (Loewus et al. 1952). The net photosynthetic rate, stomatal conductance, and transpiration rate of the youngest fully expanded leaf was measured between 10:00 a.m. and 12:00 noon using a CI-310 photosynthesis system (CID, Inc., Vancouver, WA, U.S.A.) in an open-air circulation system. The following conditions for leaf gas measurements were used: photosynthetic

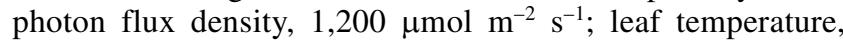
$27^{\circ} \mathrm{C}$; airflow through the cuvette, 0.3 liter $\mathrm{min}^{-1}$; and time interval, $20 \mathrm{~s}$. Measurements were carried out automatically five times. Six replicates were used for each growth parameter measurement. Each replicate was conducted with 10 seedlings. Mean and standard error values for each parameter were calculated for each control and treatment, and Student's $t$ tests were used to compare data for control plants versus BPHinfested plants.

\section{Microarray analysis.}

A subtractive cDNA library was constructed from the BPHinfested B5 and MH63 plants using SSH technique (Wang et al. 2005; Yuan et al. 2005). For the forward subtractive cDNA library of B5, cDNA obtained from B5 infested by BPH was used as a "tester" population and cDNA from MH63 and noninfested B5 was used as a "driver" population (Wang et al. 2005). In MH63, forward subtraction was performed using cDNA synthesized from BPH-infested plants as a tester and that from noninfested plants served as a driver (Yuan et al. 2005). In the reverse subtractive cDNA libraries of both genotypes, the tester and driver populations were interchanged. To reduce the bias caused by $\mathrm{SSH}$ technology, equal numbers of clones were selected randomly from each of the SSH cDNA libraries and, in total, 1,920 clones were used in the cDNA microarray analysis. The cDNA microarrays were custom made and analyzed at TaKaRa (Dalian) Co., Ltd. (Shiga, Japan). To determine the detection sensitivity limit, the polymerase chain reaction (PCR)-amplified fragment from lambda-A and Puc19 were used as external controls, and the PCR-amplified fragments from the mouse (Mus musculus) $\beta$-actin gene and human TFR gene were used as negative controls. Inserts of cDNA clones were PCR amplified with $\mathrm{T} 7$ and M13R primers. The purified PCR products were dissolved in $\mathrm{H}_{2} \mathrm{O}$ at a concentration of $1.0 \mathrm{mg} / \mathrm{ml}$ and arrayed in paired dots from 384-well microtiter plates on poly-1-Lys-coated microglass slides using a microarray stamping machine (Affymetrix 417 Arrayer; Affymetrix, Inc. Co, Santa Clara, CA, U.S.A.). Such slides were post-processed according to the manufacturer's protocols at TaKaRa Co., Ltd.

Each of the biological experiments was performed twice, in triplicate, with freshly labeled cDNA targets in each case. Targets were prepared from the total RNA isolated from more than 30 seedlings after $48 \mathrm{~h}$ of BPH treatment and corresponding controls using TRIZOL Reagent (Invitrogen, Carlsbad, CA, U.S.A.). BPH-infested samples and control samples (30 $\mu \mathrm{g}$ RNA in each case) were labeled with Cy5-Dutp and Cy3Dutp, respectively (Amersham Pharmacia Biotech, Buckinghamshire, U.K.). Each labeled target was purified using Centrisep columns and then hybridized at $65^{\circ} \mathrm{C}$ for $16 \mathrm{~h}$. Following hybridization, the slides were washed three times with a first washing solution $(2 \times \mathrm{SSC}[1 \times \mathrm{SSC}$ is $0.15 \mathrm{M} \mathrm{NaCl}$ plus $0.015 \mathrm{M}$ sodium citrate], $0.2 \%$ sodium dodecyl sulfate [SDS]) at $55^{\circ} \mathrm{C}$ for $10 \mathrm{~min}$ each time, then a second washing solution $(0.05 \times \mathrm{SSC})$ at room temperature for $10 \mathrm{~min}$, then scanned using an Affymetrix 428 Scanner.

The TIFF images were quantified using ImaGene III Software (BioDiscovery, Los Angeles). Spots that were faint in either channel, with no nonsaturated pixels in one channel, or with bad shape or severe apparent contamination were filtered out. The remaining spots were considered to be valuable and their raw signal intensity data were analyzed further to obtain their respective expression ratios (signal intensity of the treated sample/that of the control sample). The background fluorescence was calculated from the signal intensity from the negative controls (mean pixel intensity). The external controls were used to equalize hybridization signals generated from different samples. The data were normalized using the print-tiploess method in the Limma package (Smyth 2004) from the Bioconductor website (Dudoit et al. 2003). To identify the gene response to $48 \mathrm{~h}$ of BPH feeding, the Limma R package (Smyth 2004) was used to perform hypothesis tests by fitting a linear model to the expression data. During pairwise comparison between each treated sample versus the control, a moderated $t$ statistic was computed by using an empirical Bayes method to shrink the gene-wise sample variances toward a common value (Smyth 2004), and the differential level was represented by a $\log _{2}$ of intensity ratio. The $P$ value adjustment used in FDR control for multiple testing is the Benjamini and Hochberg method (Benjamini and Hochberg 2000). The genes were selected by the adjusted $P$ values less than 0.05 . To ensure further that the gene had a significantly differential expression, $P$ value less than 0.05 and greater than twofold differences in signal intensity between BPH-feeding and control samples were used. All the raw data have been deposited in the public database GEO and the accession number is GPL5443.

\section{Sequence analysis and BLAST research.}

Nucleotide sequences of the selected clones were determined using an ABI Model 377 DNA sequencer (Perkin-Elmer, Norwald, CT, U.S.A.) and an ABI PRISM Dye terminator cycle sequencing kit. The sequences were compared to all known DNA sequences in the National Center for Biotechnology Information database using BLAST programs. Sequence similarities between submitted sequences and database sequences were evaluated from their $E$ values, with values lower than $\mathrm{e}^{-8}$ being considered significant and to indicate similarity between the two sequences. The genes were functionally categorized by aligning the putative amino acid sequences with entries in the MIPS database.

\section{RNA gel-blot analysis.}

The leaves and stem of B5 and MH63 plants were sampled after 3, 6, 12, 24, 48, 72, and $96 \mathrm{~h}$ of BPH treatment. Seedlings that had not been fed upon by BPH were harvested at the same time as the controls. More than 30 rice seedlings were harvested each time. Three biological replicates were used for RNA gel-blot analysis. Total RNA (30 $\mu \mathrm{g})$ from each sample was electrophoretically separated on $1.2 \%$ (wt/vol) agarose gel containing formaldehyde and then transferred to a Hybond $\mathrm{N}^{+}$membrane. The PCR-amplified fragments prepared from the rice cDNAs were used as probes for RNA gel-blot hybridization. The PCR-amplified fragments from the rice $\beta$-actin gene were used as external controls. The probes were labeled with $\left[\alpha-{ }^{32}\right.$ P]DCTP using the Primea-Gene labeling system (Promega Corp., Madison, WI, U.S.A.). The blots were hybridized for more than $10 \mathrm{~h}$ at $65^{\circ} \mathrm{C}$ with the labeled probes. Blots were washed at $65^{\circ} \mathrm{C}$ for $15 \mathrm{~min}$ in $1 \times \mathrm{SSC}$ and $0.2 \% \mathrm{SDS}$, and then at $65^{\circ} \mathrm{C}$ for 15 min in $0.5 \times$ SSC and $0.1 \%$ SDS. After $12 \mathrm{~h}$ of exposure to storage phosphor screen, they were scanned by a Typhoon 9200 scanner (Amersham-Pharmacia, Piscataway, NJ, U.S.A.) and the acquired data were analyzed based on the bands intensities of the clones using ImageQuant software (version 5.2; Amersham-Pharmacia) and the differential level was represented by a $\log _{2}$ of intensity ratio. 
Physical clusters of BPH-induced rice genes.

The BPH-induced genes were mapped to chromosomes by using BLASTn against the Gramene genome database of rice. To determine the BPH-induced gene clusters, a formula described by Walia and associates (2005) was used. For this purpose, each chromosome was divided into nonoverlapping windows of arbitrary (1-Mb) length. The maximum distance between neighboring genes included in a cluster was restricted to $500 \mathrm{~kb}$. The colocalization of three or more genes within 1 $\mathrm{Mb}$ was indicated an obvious cluster.

\section{ACKNOWLEDGMENTS}

This research was supported by grants from the National Special Key Project on Functional Genomics and Biochip of China (2006AA10A103) and the National Natural Science Foundation of China (30570140).

\section{LITERATURE CITED}

Arnon, D. I. 1949. Copper enzymes in isolated chloroplasts. Polyphenooxidase in Beta vulgaris. Plant Physiol. 24:1-15.

Benjamini, Y., and Hochberg, Y. 2000. The adaptive control of the false discovery rate in multiple hypotheses testing. J. Behav. Educ. Stat. 25:60-83.

Bradford, M. N. 1976. A rapid and sensitive method for the quantitation of microgram quantities of protein utilizing the principle of protein-dye binding. Annu. Biochem. 72:248-254.

Cagampang, G. B., Pathak, M. D., and Juliano, B. O. 1974. Metabolic changes in the rice plant during infestation by the brown planthopper, Nilaparvata lugens Stål (Hemiptera:Delphacidae). Appl. Entomol. Zool. 9:174-184.

Chang, C. F., Wai, K. M., and Patterton, H. G. 2004. Calculating the statistical significance of physical clusters of co-regulated genes in the genome: the role of chromatin in domain-wide gene regulation. Nucleic Acids Res. 32:1798-1807.

Cho, K. S., Jung, K. W., Jeung, J. U., Kang, K. H., Shim, K. S., You, M. K., Yoo, K. S., Ok, S. H., and Shin, J. S. 2005. Analysis of differentially expressed transcripts from planthopper-infested wild rice (Oryza minuta). Plant Cell Rep. 24:59-67.

Dangl, J. L., and Jones, J. D. G. 2001. Plant pathogens and integrated defence responses to infection. Nature 411:826-833.

De Vos, M., Van Oosten, V. R., Van Poecke, R. M. P., Van Pelt, J. A., Pozo, M. J., Mueller, M. J., Buchala, A. J., Métraux, J.-P., Van Loon, L. C., Dicke, M., and Pieterse, C. M. J. 2005. Signal signature and transcriptiome changes of Arabidopsis during pathogen and insect attack. Mol. Plant-Microbe Interact. 18:923-927.

Dudoit, S., Gentleman, R. C., and Quackenbush, J. 2003. Open source software for the analysis of microarray data. Biol. Tech. Suppl. 45-51.

Ellis, C., Karafyllidis, I., and Turner, J. G. 2002. Constitutive activation of jasmonate signaling in an Arabidopsis mutant correlates with enhanced resistance to Erysiphe cichoracearum, Pseudomonas syringae, and Myzus persicae. Mol. Plant-Microbe Interact. 15:1025-1030.

Fidantsef, A. L., Stout, M. J., Thaler, J. S., Duffey, S. S., and Bostock, R. M. 1999. Signal interactions in pathogen and insect attack: expression of lipoxygenase, proteinase inhibitor II, and pathogenesis-related protein P4 in the tomato, Lycopersicon esculentum. Physiol. Mol. Plant Pathol. 54:97-114.

Frishman, D., Albermann, K., Hani, J., Heumann, K., Metanomski, A., Zollner, A., and Mewes, H. 2001. Functional and structural genomics using PEDANT. Bioinformatics 17:44-57.

Fukao, T., Xu, K., Ronald, P. C., and Bailey-Serresa, J. 2006. A variable cluster of ethylene response factor-like genes regulates metabolic and developmental acclimation responses to submergence in rice. Plant Cell 18:2021-2034.

Fulda, M., Heinz, E., and Wolter, F. P. 1997. Brassica napus cDNAs encoding fatty acyl-CoA synthetase. Plant Mol. Biol. 33:911-922.

Gholizadeh, A., Santha, I. M., Kohnehrouz, B. B., Lodha, M. L., and Kapoor, H. C. 2005. Cystatins may confer viral resistance in plants by inhibition of virus-induced cell death phenomenon in which cysteine proteinases are active: cloning and molecular characterization of a cDNA encoding cysteine-proteinase inhibitor (celostatin) from Celosia cristata (crested cock's comb). Biotechnol. Appl. Biochem. 42:197-204.

Hasegawa, T., and Horie, T. 1996. Rice leaf photosynthesis as a function of nitrogen and crop developmental stage. Jpn. J. Crop Sci. 65:553-554.

Heldt, H. W. 1997. Polysaccharides. Pages 219-246 in: Plant Biochemistry \& Molecular Biology. Oxford University Press Inc., New York.
Hirabayashi, H., and Ogawa T. 1995. RFLP mapping of Bph-1 (brown planthopper resistance gene) in rice. Breed Sci. 45:369-371.

Huang, Z., He, G. C., Shu, L. H., Li, X., and Zhang, Q. F. 2001. Identification and mapping of two brown planthopper resistance genes in rice. Theor. Appl. Genet. 102:929-934.

Jena, K. K., Jeung, J. U., Lee, J. H., Choi, H. C., and Brar, D. S. 2006. High-resolution mapping of a new brown planthopper (BPH) resistance gene, $B p h 18(\mathrm{t})$, and marker-assisted selection for $\mathrm{BPH}$ resistance in rice (Oryza sativa L.). Theor. Appl. Genet. 112(2):288-297.

Kabrick, L. R., and Backus, E. A. 1990. Salivary deposits and plant damage associated with specific probing behaviors of the potato leafhopper, Empoasca fabae, on alfalfa stems. Entomol. Exp. Appl. 56:287-304.

Kaloshian, I., and Walling, L. L. 2005. Hemipterans as plant pathogens. Annu. Rev. Phytopathol. 43:491-521.

Kaloshian, I., Kinsey, M. G., Williamson, V. M., and Ullman, D. E. 2000 $\mathrm{Mi}$-mediated resistance against the potato aphid Macrosiphum euphorbiae (Hemiptera, Aphididae) limits sieve element ingestion. Environ. Entomol. 29:690-695.

Kempema, L. A., Cui, X., Holzer, F. M., and Walling, L. L. 2007. Arabidopsis transcriptome changes in response to phloem-feeding silverleaf whitefly nymphs. Similarities and distinctions in responses to aphids. Plant Physiol. 143:849-865.

Li, L., Zhao, Y., McCaig, B. C., Wingerd, B. A., Wang, J., Whalon, M. E., Pichersky, E., and Howe, G. A. 2004. The tomato homolog of CORONATINE-INSENSITIVE 1 is require for the maternal control of seed maturation, jasmonate-signaled defense responses, and glandular trichome development. Plant Cell 16:126-143.

Li, Q., Lee, B. T. K., and Zhang, L. 2005. Genome-scale analysis of the positional clustering of mouse testis-specific genes. BMC Genomics 6:7.

Loewus, F. A. 1952. Improvement in the anthrone method for determination of carbohydrates. Anal. Chem. 24:219.

Makino, A., Mae, T., and Ohira, K. 1983. Photosynthesis and ribulose-1, 5-bisphosphate carboxylase in rice leaves: changes in photosynthesis and enzymes involved in carbon assimilation from leaf development through senescence. Plant Physiol. 73:1002-1007.

Martinez de Ilarduya, O., Xie, Q. G., and Kaloshian, I. 2003. Aphidinduced defense responses in $M i$-1-mediated compatible and incompatible tomato interactions. Mol. Plant-Microbe Interact. 16:699-708.

Matthews, R. E. F. 1991. Relationships between plant viruses and invertebrates. Pages 520-561 in: Plant Virology, Volume 3. R. E. F. Matthews, ed. Academic Press, New York.

Moran, P. J., and Thompson, G. A. 2001. Molecular responses to aphid feeding in Arabidopsis in relation to plant defense pathways. Plant Physiol. 125:1074-1085.

Moran, P. J., Cheng, Y., Cassell, J. L., and Thompson, G. A. 2002. Gene expression profiling of Arabidopsis thaliana in compatible plant-aphid interactions. Arch. Insect Biochem. Physiol. 51:182-203.

Park, S. J., Huang, Y., and Ayoubi, P. 2006. Identification of expression profiles of sorghum genes in response to greenbug phloem-feeding using cDNA subtraction and microarray analysis. Planta 223:932-947.

Plaxton, W. C. 1996. The organization and regulation of plant glycolysis. Annu. Rev. Plant Physiol. Plant Mol. Biol. 47:185-214.

Qubbaj, T., Reineke, A., and Zebitz, C. P. W. 2005. Molecular interactions between rosy apple aphids, Dysaphis plantaginea, and resistant and susceptible cultivars of its primary host Malus domestica. Entomol. Exp. Appl. 115:145-152.

Ren, X., Weng, Q., Zhu, L., and He, G. 2004. Dynamic mapping of quantitative trait loci for brown planthopper resistance in rice. Cereal Res. Commun. 32(1):31-38

Rossignol, M., Peltier, J. B., Mock, H. P., Matros, A., Maldonado, A. M., and Jorrín, J. V. 2006. Plant proteome analysis: a 2004-2006 update. Proteomics 6:5529-5548.

Rubia-Sanchez, E., Suzuki, Y., Arimura, K., Miyamoto, K., Matsumura, M., and Watanabe, T. 2003. Comparing Nilaparvata lugens (Stål) and Sogatella furcifera (Horvath) (Homoptera: Delphacidae) feeding effects on rice plant growth processes at the vegetative stage. Crop Prot. 22:967-974.

Scheideler, M., Schlaich, N. L., Fellenberg, K., Beissbarth, T., Hauser, N. C., Vingron, M., Slusarenko, A. J., and Hoheisel, J. D. 2002. Monitoring the switch from the housekeeping to pathogen defense metabolism in Arabidopsis thaliana using cDNA arrays. J. Biol. Chem. 277:1055510561.

Smyth, G. K. 2004. Linear models and empirical Bayes methods for assessing differential expression in microarray experiments. Stat. Appl Genet. Mol. Biol. 3:Article 3.

Sogawa, K. 1982. The rice brown planthopper: feeding physiology and host plant interactions. Annu. Rev. Entomol. 27:49-73.

Sogawa, K. 1994. Feeding behaviour and damage mechanism of the rice planthoppers. Pages 143-154 in: Analysis of Damage Mechanisms by 
Pests and Diseases and Their Effects on Rice Yield. A. Elings and E. G. Rubia, eds. SARP Res. Proc. Wageningen, The Netherlands.

Spellman, P. T., and Rubin, G. M. 2002. Evidence for large domains of similarly expressed genes in the Drosophila genome. J. Biol. 1:5.

Tan, G. X., Weng, Q. M., Ren, X., Huang, Z., Zhu, L. L., and He, G. C. 2004. Two whitebacked planthopper resistance genes in rice share the same loci with those for brown planthopper resistance. Heredity 92:212-217.

Thompson, G. A., and Goggin, F. L. 2006. Transcriptomics and functional genomics of plant defence induction by phloem-feeding insects. J. Exp. Bot. 57:755-766.

van de Ven, W. T. G., LeVesque, C. S., Perring, T. M., and Walling, L. L. 2000. Local and systemic changes in squash gene expression in response to silverleaf whitefly feeding. Plant Cell. 12:1409-1423.

Voelckel, C., Weisser, W. W., and Baldwin, I. T. 2004. An analysis of plant-aphid interactions by different microarray hybridization strategies. Mol. Ecol. 13:3187-3195.

Walia, H., Wilson, C., Condamine, P., Liu, X., Ismail, A. M., Zeng L., Wanamaker, S. I., Mandal, J., Xu, J., Cui, X., and Close T. J. 2005. Comparative transcriptional profiling of two contrasting rice genotypes under salinity stress during the vegetative growth stage. Plant Physiol. 139:822-835.

Walling, L. L. 2000. The myriad plant responses to herbivores. J. Plant Growth Regul. 19:195-216.

Wang, X. L., He, R. F., and He, G. C. 2005. Construction of suppression subtractive hybridization libraries and identification of brown planthopper-induced genes. J. Plant Physiol. 162:1254-1262.

Watanabe, T., and Kitagawa H. 2000. Photosynthesis and translocation of assimilates in rice plants following phloem feeding by the planthopper Nilaparvata lugens (Homoptera: Delphacidae). J. Econ. Entomol. 93:1192-1198.

Watanabe, T., Fabellar, L. T., Almazan, L. P., Rubia, E. G., Heong, K. L., and Sogawa, K. 1997. Quantitative evaluation of growth and yield of rice plants infested with rice planthoppers. Pages 365-382 in: Applications of Systems Approaches at the Field Level. M. J. Kropff, P. S. Teng, P. K. Aggarwal, J. Bouma, B. A. M. Bouman, J. W. Jones, and H. H. van Laar, eds. Kluwer Academic Publishers, Dordrecht, The Netherlands.
Wu, J. C., Qiu, H. M., Yang, G. Q., Dong, B., and Gu, H. N. 2003. Nutrient uptake of rice roots in response to infestation of Nilaparvata lugens (Stål) (Homoptera: Delphacidae). J. Econ Entomol. 96(6):1798-1804.

Wu, J. C., Qiu, Z. H. J., Ying, L., Dong, B., and Gu, H. N. 2004. Changes of zeatin riboside content in rice plants due to infestation by Nilaparvata lugens (Stål ) (Homoptera: Delphacidae). J. Econ. Entomol. 97(6):1917-1922.

Yang, C. J., Yang, Z. H., Hu, J. F., He, G. C., and Shu, L. H. 1999. On the brown planthopper resistant in introgressive lines from wild rice. Acta. Phytophylacica Sin. 26:197-202.

Yang, H., Ren, X., Weng, Q., Zhu, L., and He, G. 2002. Molecular mapping and genetic analysis of a rice brown planthopper (Nilaparvata lugens Stål.) resistance gene. Hereditas 136:39-43.

Yuan, H. Y., Chen, X. P., Zhu, L. L., and He, G. C. 2005. Identification of genes responsive to brown planthopper Nilaparvata lugens Stål (Homoptera: Delphacidae) feeding in rice. Planta 221:105-112.

Zarate, S. I., Kempema, L. A., and Walling, L. L. 2007. Silverleaf whitefly induces salicylic acid defenses and suppresses effectual jasmonic acid defenses. Plant Physiol. 143:866-875.

Zhang, F., Zhu, L., and He, G. 2004. Differential gene expression in response to brown planthopper feeding in rice. J. Plant Physiol. 161:53-62.

Zhu, D., and Kang, Y. 1996. On the methods of measurement of leaf area in rice. Acta. Agric. Shanghai 12:82-85.

Zhu-Salzman, K., Salzman, R. A., Ahn, J., and Koiwa, H. 2004. Transcriptional regulation of sorghum defense determinants against a phloemfeeding aphid. Plant Physiol. 134:420-431.

Zielinski. R. E. 1998. Calmodulin and calmodulin-binding proteins in plants. Annu. Rev. Plant Physiol. Plant Mol. Biol. 49:697-725.

\section{AUTHOR-RECOMMENDED INTERNET RESOURCES}

Bioconductor, open source software for bioinformatics website: www.bioconductor.org

MIPS database: www.mips.biochem.mpg.de

National Center for Biotechnology Information: www.ncbi.nlm.gov

Rice genome database: www.gramene.org 